\title{
Men's perspectives on HIV self-testing in sub-Saharan Africa: a systematic review and meta-synthesis
}

Mbuzeleni Hlongwa ${ }^{1 *} \mathbb{D}$, Tivani Mashamba-Thompson ${ }^{1,2}$, Sizwe Makhunga ${ }^{1}$, Claudine Muraraneza $^{1}$ and Khumbulani Hlongwana ${ }^{1}$

\begin{abstract}
Background: Despite the many HIV testing models implemented in Africa, the level of HIV testing uptake remains relatively poor, especially among men. The HIV self-testing (HIVST) model offers an additional approach for encouraging men to get tested. This study aimed to synthesise evidence on men's perspectives regarding HIVST in sub-Saharan Africa (SSA).

Methods: The databases searched included PubMed/MEDLINE, American Doctoral Dissertations via EBSCO host; Union Catalogue of Theses and Dissertations; SA ePublications via SABINET Online; World Cat Dissertations; Theses via OCLC; ERIC; CINAH; PsychInfo; Embase, Sociological Abstract, Scopus; and Google Scholar. The World Health Organization (WHO) and The Joint United Nations' Programme on HIV and AIDS (UNAIDS) websites were further searched. We only extracted qualitative information from the included studies, despite the research method used (qualitative or mixed methods). The Preferred Reporting Items for Systematic Reviews and Meta-Analysis (PRISMA), as well as the Mixed Method Appraisal Tool (MMAT) version 2018, were used to determine the methodological quality of the included studies. NVivo version 11 was used for thematic analysis.

Results: A total of 21,184 articles were identified by the initial search criteria, but only 16 articles were included in the data extraction and quality assessment stage. The following key themes emerged: knowledge of HIVST; acceptability of HIVST; need for HIVST counselling; confidentiality of HIVST; convenience of HIVST; and accuracy of HIVST. The study shows that while HIVST provides men with an alternative, confidential and convenient testing model, the potential for psychological and physical harm remains a challenge.

Conclusion: The introduction of the HIVST strategy has the potential of improving men's uptake in HIV testing services, thereby contributing towards addressing the first cascade of the 90-90-90 strategy. While HIVST has a potential for addressing men's barriers to attending clinic settings, such as confidentiality and convenience, it barely addresses the HIVST counselling and accuracy concerns.
\end{abstract}

Keywords: HIV testing, HIV self-testing, HIVST, Men, Males, Sub-Saharan Africa

\footnotetext{
* Correspondence: hlongwa.mbu@gmail.com

'Discipline of Public Health Medicine, School of Nursing and Public Health,

University of KwaZulu-Natal, Durban, South Africa

Full list of author information is available at the end of the article
}

(c) The Author(s). 2020 Open Access This article is distributed under the terms of the Creative Commons Attribution 4.0 International License (http://creativecommons.org/licenses/by/4.0/) which permits unrestricted use, distribution, and reproduction in any medium, provided you give appropriate credit to the original author(s) and the source, provide a link to the Creative Commons license, and indicate if changes were made. The Creative Commons Public Domain Dedication waiver (http://creativecommons.org/publicdomain/zero/1.0/) applies to the data made available in this article, unless otherwise stated. 


\section{Background}

There remains a noticeable gender gap as far as the rates of HIV testing uptake in SSA are concerned, with men remaining harder to reach for HIV testing than their female counterparts [1]. There are many factors that affect men's uptake of HIV testing services in healthcare clinics, including stigma and confidentiality-related fears [2]. Due to men's reluctance to visit healthcare facilities [2], there remains a high proportion of HIV positive men who are unaware of their HIV status, some of whom engage in risky sexual intercourse, thereby exposing more women, as well as other men in cases of men who are having sex with other men (MSM), to new HIV infections, which in turn threatens to undermine the progress made towards addressing the HIV epidemic [3]. Men living with HIV are more likely to die early compared to their female counterparts, owing to late diagnosis and antiretroviral therapy (ART) being initiated when the HIV is already at an advanced stage [4-6]. This suggests a particular urgency in regard to designing and implementing innovative strategies to target men for HIV testing services in resource-limited settings in order to address the first cascade of the UNAIDS 90-90-90 programme (90\% of all people living with HIV should be diagnosed, $90 \%$ of people diagnosed with HIV should be started on ART, and $90 \%$ of people started on ART should have a suppressed viral load) [7].

The community and home-based HIV counselling and testing models [8-10] in particular have made some strides towards improving the uptake of HIV testing among men in SSA. However, these strategies become ineffective in highly mobile communities [10]. HIV selftesting (HIVST) offers a new approach to improving men's HIV testing rates and removing some of the barriers associated with accessing clinic-based HIV testing services by enabling individuals to conduct and interpret their own HIV tests at their own convenient time and in a private space [11-13], whereas HIV self-sampling occurs when individuals collect their own samples (usually blood) and send their specimen to a laboratory for analysis [14]. HIVST can be administered orally (using saliva) or through finger-pricking (drawing of blood). Individuals administer HIVST with little or no training, although written instructions and warnings are provided with the kit. Some of the notable arguments against HIVST involve its high costs, insufficient counselling, and missed opportunities for STI screening [15]. Despite these arguments, HIVST has been shown to be widely acceptable in SSA [11, 12, 16], as well as among key population groups [13]. However, this acceptability has not seemed to have translated into an increase in the uptake of HIVST, especially among men in SSA.

Furthermore, the research evidence regarding men's perspectives towards HIVST, globally and SSA in particular, remains limited [12]. While more studies are being conducted to develop understanding of HIVST and innovative methods towards hard-to-reach populations globally, similar studies are also necessary for SSA [12]. In SSA, the limited literature on HIVST may be due to the fact that the adoption of HIVST is a recent development. The first phase of the HIVST initiative began in 2015 in SSA and is currently implemented in the following countries: Malawi, Zambia, Zimbabwe, South Africa, Lesotho, and Swaziland. Close to 5 million (4.8 million) HIVST kits in total are expected to be distributed in these countries by the year 2020 [17]. We could not find a similar review which focused solely on qualitative synthesis in SSA to explore men's perspectives on HIVST using a systematic review and meta-synthesis research method. This study aims to synthesise evidence on men's perspectives regarding HIVST in SSA.

\section{Methods \\ Design}

A systematic search to synthesise qualitative literature for published and unpublished (grey literature) articles was undertaken. Researchers currently working on HIV self-testing in SSA were contacted in an attempt to obtain unpublished articles. The research question aimed to consider studies including qualitative data, but not limited to designs such as phenomenology, grounded theory, ethnography, and action research. Descriptive qualitative studies describing men's experiences, perspectives, or the effects of the experience of HIVST were considered. Studies including qualitative data were more suitable for this review to explore and synthesise men's opinions and/or experiences of HIVST. The review protocol was published apriori [18]. The Preferred Reporting Items for Systematic Reviews and MetaAnalyses (PRISMA) guidelines [19] and the Population, Concept, and Context (PCC) framework for determining the eligibility of research question (Table 1) were followed. Since this study utilised a secondary synthesis of data, which is already in the public domain, ethical approvals and consent to participate were not necessary.

\section{Identifying the research question}

The main research question was: What is the evidence of men's perspectives on HIVST in SSA?

Table 1 PCC framework

\begin{tabular}{ll}
\hline Criteria & Determinants \\
\hline Population & Men of all age groups in SSA \\
Concept & HIV self-testing among men \\
Context & HIV/AIDS \\
\hline
\end{tabular}




\section{Suitability of the question for a systematic review Search strategy}

A comprehensive electronic search strategy was conducted in order to identify all relevant grey literature and published studies between January 2005 and February 2019. The search criteria included all studies from this period because studies conducted before 2005 would not reflect key information pertaining to the HIVST model in SSA, mainly due to HIVST being only recently adopted in SSA. However, it was noted that almost all included studies (94\%) on HIVST were conducted from 2015 onwards. As part of the search, twelve electronic databases were searched in February 2019: PubMed/MEDLINE, American Doctoral Dissertations via EBSCO host, Union Catalogue of Theses and Dissertations (UCTD); SA ePublications via SABINET Online and World Cat Dissertations; Theses via OCLC; ERIC; CINAH; PsychInfo; Embase, Sociological Abstract, Scopus and Google Scholar. The Medical Research Council (MRC) and Human Sciences Research Council (HSRC) publications, as well as websites from the World Health Organization (WHO) and the Joint United Nations Programme on HIV/AIDS (UNAIDS) were also searched. The reference list of all studies eligible for inclusion were screened for potential additional studies. Boolean terms (AND, OR) and Medical Subject Headings $(\mathrm{MeSH})$ terms formed part of our search strategy. The key search words used were; 'HIV testing', 'HIV self-testing', 'HIV self- testing', 'Men', 'Male', 'sub-Saharan Africa'. Sub-Saharan African country names, and truncated terms such as 'west-Africa' were also used to ensure that articles indexed using SSA country-specific names or regional terms were retrieved (Appendix). Studies obtained through database searches were exported to Endnote version 7 library for further abstract and full article screening, respectively [20]. The EndNote library "Find full text" option was used to automatically download PDFs of exported studies.

\section{Study selection and inclusion criteria}

The database search was initially conducted against a broad inclusion criterion by the first reviewer $(\mathrm{MH})$. This focused on the title of the articles. All articles identified to be potentially eligible for inclusion in this study were obtained in full texts. Two independent reviewers ( $\mathrm{MH}$ and SM) then conducted abstracts and full article screenings to identify articles that met all the following inclusion criteria:

- Studies focused on HIVST.

- Articles presented the approach of qualitative data.

- Studies were published between January 2005 and February 2019.
- Articles were conducted in SSA and published in any language, including English.

- Sample either male-only or mixed genders (but with explicit evidence on men).

Those studies published prior to 2005 and those conducted outside of SSA were excluded. Also excluded were studies which did not offer clear and explicit qualitative information on men, despite the research method used.

\section{Quality appraisal}

Methodological rigor in this review was achieved by having two independent reviewers critically appraising the methodological validity of the included studies. A MixedMethod Appraisal Tool (MMAT), version 2018 [21], was adopted. The MMAT is a critical appraisal tool that has been designed for the appraisal stage of systematic mixed study reviews, like reviews that include qualitative, quantitative, and mixed methods studies (both qualitative and quantitative) (Table 2). The tool helps users to appraise the methodological quality of five categories in studies: (a) qualitative research, (b) randomised controlled trials, (c) non-randomised studies, (d) quantitative descriptive studies, and (e) mixed methods studies. The MMAT tool was used in this study to assess (a) whether each study's qualitative approach and data collection methods were appropriate to answer the research question; (b) whether the study findings were adequately derived from the data; (c) whether the interpretation of results was sufficiently substantiated by the data; as well as (d) whether there was coherence between qualitative data sources, collection, analysis, and interpretation [21].

All included articles underwent the initial two screening questions which would indicate whether further methodological quality appraisal was feasible or appropriate. If responses to the initial screening questions were either 'no' or 'can't tell' they were excluded from further screening. Qualitative articles were screened with questions three to seven (Table 2). Mixed methods studies were screened with questions eight to twelve. Almost all included studies scored $100 \%$, with just one study scoring 86\% [11]. Articles that would score below 50\% on the methodological quality assessment were going to be excluded to ensure that included studies had a strong methodological rigor to answer this study's research question. However, none of the articles were excluded at the methodological quality assessment stage.

\section{Data extraction}

A data collection instrument (using Google Forms) was developed to confirm the study characteristics as well as relevance. The data extraction tool used the following elements: (a) author(s) and date of publication, (b) aim(s) or research questions, (c) primary source data (e.g. quotes 
Table 2 Methodological quality assessment

\begin{tabular}{|c|c|c|c|c|c|c|c|c|c|c|c|c|c|}
\hline & Q1 & Q2 & Q3 & Q4 & Q5 & Q6 & Q7 & Q8 & Q9 & Q10 & Q11 & Q12 & Score \\
\hline Chipungu et al., 2017 & y & y & $\mathrm{n} / \mathrm{a}$ & $\mathrm{n} / \mathrm{a}$ & $\mathrm{n} / \mathrm{a}$ & $\mathrm{n} / \mathrm{a}$ & $\mathrm{n} / \mathrm{a}$ & y & y & y & y & y & $100 \%$ \\
\hline Choko et al., 2011 & y & y & $\mathrm{n} / \mathrm{a}$ & n/a & $\mathrm{n} / \mathrm{a}$ & n/a & $\mathrm{n} / \mathrm{a}$ & y & y & y & y & $\mathrm{n}$ & $86 \%$ \\
\hline Indravudh et al., 2017 & y & $y$ & $\mathrm{n} / \mathrm{a}$ & $\mathrm{n} / \mathrm{a}$ & $\mathrm{n} / \mathrm{a}$ & n/a & $\mathrm{n} / \mathrm{a}$ & y & y & y & y & y & $100 \%$ \\
\hline Ritchwood et al., 2019 & y & $y$ & $\mathrm{n} / \mathrm{a}$ & $\mathrm{n} / \mathrm{a}$ & $\mathrm{n} / \mathrm{a}$ & $\mathrm{n} / \mathrm{a}$ & $\mathrm{n} / \mathrm{a}$ & y & y & y & y & y & $100 \%$ \\
\hline Burke et al., 2017 & y & y & y & y & y & y & y & $n / a$ & n/a & $n / a$ & $\mathrm{n} / \mathrm{a}$ & $\mathrm{n} / \mathrm{a}$ & $100 / \%$ \\
\hline Choko et al., 2017 & y & y & y & y & y & y & y & $n / a$ & n/a & $n / a$ & n/a & n/a & $100 \%$ \\
\hline Conserve et al., 2018 & y & y & y & y & y & y & y & $n / a$ & $n / a$ & $n / a$ & n/a & $\mathrm{n} / \mathrm{a}$ & $100 \%$ \\
\hline Conserve et al., 2018 & y & y & y & y & y & y & y & $n / a$ & n/a & $n / a$ & n/a & n/a & $100 \%$ \\
\hline Harichund et al., 2018 & y & y & y & y & y & y & y & $n / a$ & $n / a$ & $n / a$ & $n / a$ & $\mathrm{n} / \mathrm{a}$ & $100 \%$ \\
\hline Jennings et al., 2017 & y & y & y & y & y & y & y & $n / a$ & n/a & $n / a$ & $\mathrm{n} / \mathrm{a}$ & $\mathrm{n} / \mathrm{a}$ & $100 \%$ \\
\hline Kelvin et al., 2016 & y & y & y & y & y & y & y & $n / a$ & $n / a$ & $n / a$ & $n / a$ & $\mathrm{n} / \mathrm{a}$ & $100 \%$ \\
\hline Knight et al., 2017 & y & y & y & y & y & y & y & $n / a$ & n/a & $n / a$ & $n / a$ & $\mathrm{n} / \mathrm{a}$ & $100 \%$ \\
\hline Makusha et al., 2015 & y & y & y & y & y & y & y & $n / a$ & $n / a$ & $n / a$ & $n / a$ & $\mathrm{n} / \mathrm{a}$ & $100 \%$ \\
\hline Martinez Perez et al., 2016 & y & y & y & y & y & y & y & $\mathrm{n} / \mathrm{a}$ & $\mathrm{n} / \mathrm{a}$ & $\mathrm{n} / \mathrm{a}$ & $\mathrm{n} / \mathrm{a}$ & $\mathrm{n} / \mathrm{a}$ & $100 \%$ \\
\hline Matovu et al., 2018 & y & y & y & y & y & y & y & $\mathrm{n} / \mathrm{a}$ & $\mathrm{n} / \mathrm{a}$ & $\mathrm{n} / \mathrm{a}$ & $\mathrm{n} / \mathrm{a}$ & $\mathrm{n} / \mathrm{a}$ & $100 \%$ \\
\hline Ngure et al., 2017 & y & $y$ & y & y & y & y & $y$ & $\mathrm{n} / \mathrm{a}$ & $\mathrm{n} / \mathrm{a}$ & $\mathrm{n} / \mathrm{a}$ & $\mathrm{n} / \mathrm{a}$ & $\mathrm{n} / \mathrm{a}$ & $100 \%$ \\
\hline
\end{tabular}

*Y yes; *N no; $C$ can't tell

Screening questions (for all types)

- Q1: Are there clear research questions?

- Q2: Do the collected data allow to address the research questions?

Qualitative

- Q3: Is the qualitative approach appropriate to answer the research question?

- Q4: Are the qualitative data collection methods adequate to address the research question?

- Q5: Are the findings adequately derived from the data?

- Q6: Is the interpretation of results sufficiently substantiated by data?

- Q7: Is there coherence between qualitative data sources, collection, analysis and interpretation?

Mixed methods

- Q8: Is there an adequate rationale for using a mixed methods design to address the research question?

- Q9: Are the different components of the study effectively integrated to answer the research question?

- Q10: Are the outputs of the integration of qualitative and quantitative components adequately interpreted?

- Q11: Are divergences and inconsistencies between quantitative and qualitative results adequately addressed?

- Q12: Do the different components of the study adhere to the quality criteria of each tradition of the methods involved?

from individuals), (d) study population, (e) mean age of participants, (f) gender, $(\mathrm{g})$ percentage of women, $(\mathrm{h})$ percentage of men, (i) geographic setting (rural/urban), (j) study design, (k) type of Intervention and outcomes, (l) most relevant finding, (m) most significant finding, (n) study limitations and implications, as well as (o) interpretations and conclusions from the authors.

\section{Qualitative synthesis}

A thematic synthesis approach that broadly followed the theory outlined by Thomas and Harden (2008) for systematic reviews [22] was used. The theory was developed to address systematic review questions relating to interventions need, appropriateness and acceptability, and effectiveness while ensuring that the key principles developed in systematic reviews were not compromised [22]. Using NVivo version 11 software [23], two independent reviewers ( $\mathrm{MH}$ and $\mathrm{SM}$ ) followed the three stages outlined by the thematic synthesis theory: (a) coded the findings of the included studies line-by-line; (b) organised these free codes into related areas to construct descriptive themes; and (c) developed analytical themes [22]. The outcome of coding was verified and discussed with TM-T, a senior researcher and lecturer who also co-authored the manuscript. The process of cross-checking the outcome of coding involved a thorough discussion on the key components of each included article, such as the study aim, setting, number of participants, data analysis method, main findings (themes), limitations, and conclusions.

\section{Results}

The electronic search strategy identified 21,184 references (Fig. 1), which were screened for titles. 18,824 articles were not selected during the database search stage because they did not meet the inclusion criteria. Fourteen duplicates were removed, leaving 2346 articles which were screened for abstracts. A total of 2294 articles were removed at the abstract screening stage because they formed part of the exclusion criteria (i.e. those published prior to 2005, those conducted outside of SSA, and those without qualitative information on 


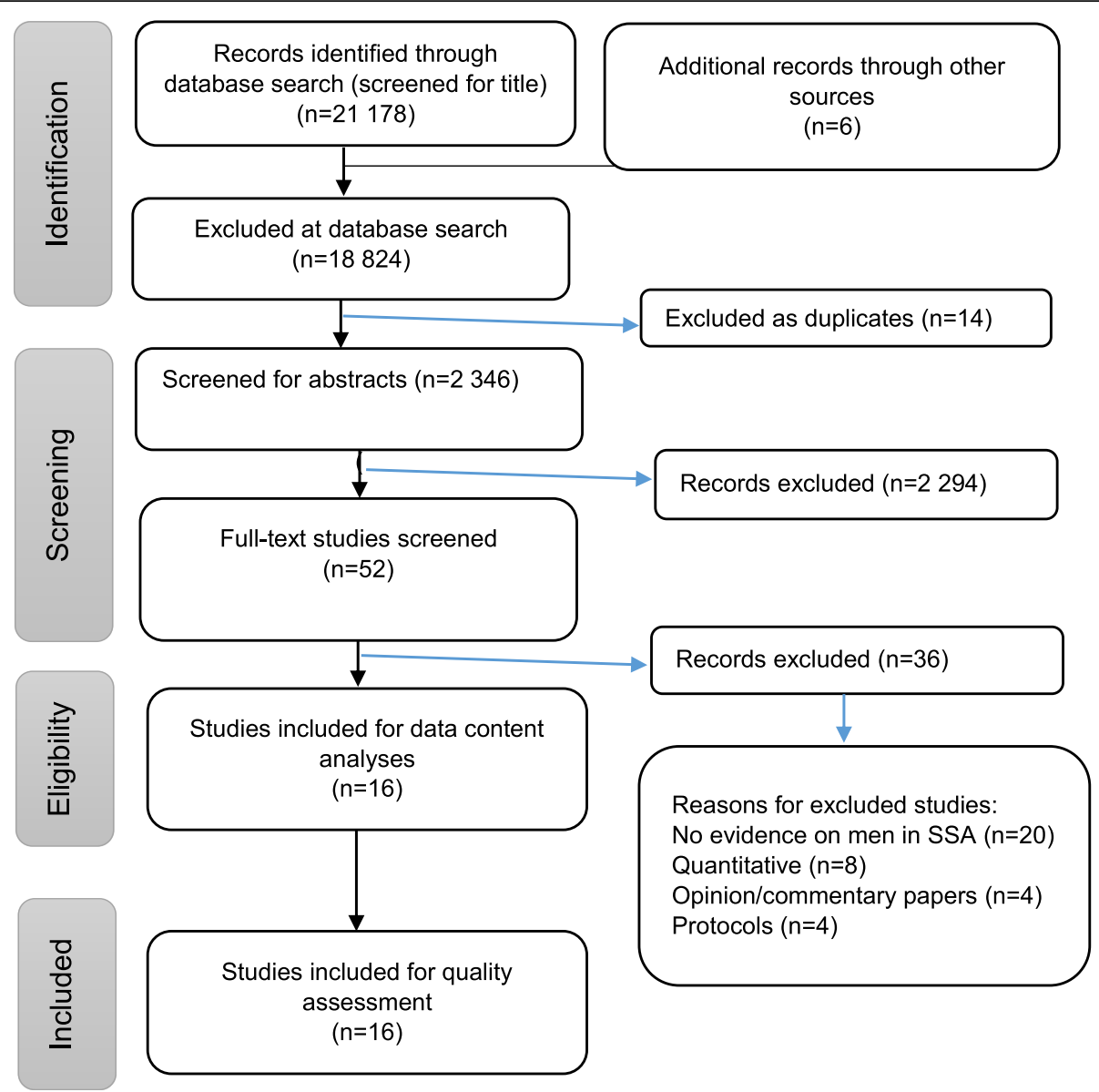

Fig. 1 PRISMA flow diagram of the study selection process

men). The researchers further screened 52 full-text articles and excluded 36 of them for the following reasons: eight were quantitative, four were opinion/commentary papers, four were study protocols, and 20 did not present evidence on men in SSA. Therefore, sixteen articles met our inclusion criteria and were included in the quality assessment stage.

\section{The characteristics of included studies}

As a result of the research method used (qualitative or mixed methods), qualitative data from the sixteen included studies were extracted. The included studies were conducted in the following countries: Zambia [24], Malawi [11, 25], South Africa [12, 26-30], Tanzania [31-33], Uganda [34, 35], Zimbabwe and Malawi [36], and Kenya [37]. Twelve studies were predominantly qualitative and four were mixed methods. Quantitative data was not analysed because it was not relevant. Six studies had samples containing males only and ten containing males and females. The samples were predominantly users of HIVST. The search criteria focused on studies published from January 2005 to February
2019 , with $94 \%$ of the included studies having been published from 2015 onwards. This was expected, given the fact that HIVST is still in the development stage in SSA. The characteristics of the included studies are shown in Table 3.

\section{Key themes}

The following main themes emerged from the included studies: knowledge of HIVST; acceptability of HIVST; the need for HIVST counselling; confidentiality of HIVST; the convenience of HIVST; and the accuracy of HIVST.

\section{Knowledge of HIVST}

Evidence on knowledge of HIVST was reported on in four articles [12, 31-33]. In two studies conducted in Tanzania, the majority of the men had no prior knowledge of HIVST [31, 32]. Poor knowledge of HIVST was also noted in another study conducted in South Africa [12].

"I have not heard about it (HIVST). For me, I would not have thought that this is something that you can have access to so easily" [ [12], p. 3]. 
Table 3 Characteristics of included studies

\begin{tabular}{|c|c|c|c|c|c|c|}
\hline $\begin{array}{l}\text { Author \& } \\
\text { year }\end{array}$ & Country & Study aim & Sample & $\begin{array}{l}\text { Number of } \\
\text { participants }\end{array}$ & Age group & Research Method \\
\hline $\begin{array}{l}\text { Burke et al., } \\
2017\end{array}$ & Uganda & $\begin{array}{l}\text { To examine values and preferences related } \\
\text { to HIVST among community members and } \\
\text { health care providers in both mainland } \\
\text { and high-risk fishing populations, including } \\
\text { with sex workers and fishermen, in Rakai } \\
\text { District, Uganda }\end{array}$ & $\begin{array}{l}\text { Males } \\
\& \\
\text { females }\end{array}$ & $\begin{array}{l}\text { Interviews: } \\
11 \text { - females } \\
10-\text { males } \\
12 \text { healthcare } \\
\text { providersFGDs: } 30- \\
\text { males } \\
25 \text { - females }\end{array}$ & $\begin{array}{l}\text { Not } \\
\text { specified }\end{array}$ & $\begin{array}{l}\text { Qualitative (interviews } \\
\text { \& focus group } \\
\text { discussions) }\end{array}$ \\
\hline $\begin{array}{l}\text { Chipungu } \\
\text { et al., } 2017\end{array}$ & Zambia & $\begin{array}{l}\text { To examine the intention to link to care } \\
\text { amongst potential HIVST users and the } \\
\text { suitability of three linkage to care } \\
\text { strategies in Lusaka Province, Zambia }\end{array}$ & $\begin{array}{l}\text { Males } \\
\& \\
\text { females }\end{array}$ & $\begin{array}{l}\text { Quantitative: } 1617 \\
\text { (60\% females, } 40 \% \\
\text { males) Qualitative: } 64 \\
\text { participants }\end{array}$ & $16-49$ years & $\begin{array}{l}\text { Mixed methods: } \\
\text { Quantitative (cross } \\
\text { sectional survey) \& } \\
\text { qualitative (focus } \\
\text { group discussions) }\end{array}$ \\
\hline $\begin{array}{l}\text { Choko } \\
\text { et al., } 2011\end{array}$ & Malawi & $\begin{array}{l}\text { To investigate the potential of supervised } \\
\text { oral HIV self-testing in Blantyre, Malawi. }\end{array}$ & $\begin{array}{l}\text { Males } \\
\& \\
\text { females }\end{array}$ & $\begin{array}{l}\text { Quantitative: } \\
147 \text { - females } \\
136 \text { - males } \\
\text { Qualitative: } 72 \\
\text { participants ( } 6 \text { groups } \\
\text { of } 12 \text { participants } \\
\text { each) }\end{array}$ & $\begin{array}{l}\text { Median } \\
\text { age }=27 \\
\text { years }\end{array}$ & $\begin{array}{l}\text { Mixed methods: } \\
\text { Quantitative (cross- } \\
\text { sectional) \& qualitative } \\
\text { (interviews) }\end{array}$ \\
\hline $\begin{array}{l}\text { Choko } \\
\text { et al., } 2017\end{array}$ & Malawi & $\begin{array}{l}\text { To describe the views of pregnant women } \\
\text { and their male partners on HIV self-test kits } \\
\text { that are woman-delivered, alone or with } \\
\text { an additional intervention. }\end{array}$ & $\begin{array}{l}\text { Males } \\
\& \\
\text { females }\end{array}$ & $\begin{array}{l}31-\text { females } \\
31-\text { males }\end{array}$ & $\begin{array}{l}\text { Median age } \\
\text { for men: } \\
28.5 \text { years; } \\
\text { women: } \\
23.5 \text { years }\end{array}$ & $\begin{array}{l}\text { Qualitative (focus } \\
\text { group discussions \& } \\
\text { in-depth interviews) }\end{array}$ \\
\hline $\begin{array}{l}\text { Conserve } \\
\text { et al., } 2018\end{array}$ & Tanzania & $\begin{array}{l}\text { To investigate the reasons and strategies } \\
\text { men used to encourage their peers to test } \\
\text { for HIV and the outcomes in order to } \\
\text { inform the development of a social } \\
\text { network-based HIVST intervention for men } \\
\text { called STEP (Self-Testing Education and } \\
\text { Promotion) }\end{array}$ & Males & 23 & $\begin{array}{l}\text { Mean age: } \\
27.3 \text { years }\end{array}$ & Qualitative (interviews) \\
\hline $\begin{array}{l}\text { Conserve } \\
\text { et al., } 2018\end{array}$ & Tanzania & $\begin{array}{l}\text { To assess men's attitudes and personal } \\
\text { agency towards HIV self-testing (HIVST) } \\
\text { and confirmatory HIV testing in order to } \\
\text { inform the development of the Tanzania } \\
\text { STEP (Self-Testing Education and } \\
\text { Promotion) Project, a peer-based HIV } \\
\text { self-testing intervention for young men in } \\
\text { Tanzania }\end{array}$ & Males & 23 & $\begin{array}{l}\text { Mean age: } \\
27.3 \text { years }\end{array}$ & Qualitative (interviews) \\
\hline $\begin{array}{l}\text { Harichund } \\
\text { et al., } 2018\end{array}$ & $\begin{array}{l}\text { South } \\
\text { Africa }\end{array}$ & $\begin{array}{l}\text { To assess whether men or women in KwaZulu- } \\
\text { Natal displayed a higher acceptance of HIVST and } \\
\text { also explored factors that influenced and } \\
\text { motivated their acceptability. }\end{array}$ & $\begin{array}{l}\text { Males } \\
\& \\
\text { females }\end{array}$ & $\begin{array}{l}12 \text {-males; } \\
28 \text {-females }\end{array}$ & $\begin{array}{l}\text { men: } 19-37 \\
\text { years; } \\
\text { women: } 18- \\
37 \text { years }\end{array}$ & $\begin{array}{l}\text { Qualitative (in-depth } \\
\text { interviews, Focus } \\
\text { group discussions) }\end{array}$ \\
\hline $\begin{array}{l}\text { Indravudh } \\
\text { et al., } 2017\end{array}$ & $\begin{array}{l}\text { Malawi \& } \\
\text { Zimbabwe }\end{array}$ & $\begin{array}{l}\text { To identify young people's preferences for HIV self- } \\
\text { testing (HIVST) delivery, determines the relative } \\
\text { strength of preferences and explores underlying } \\
\text { behaviours and perceptions to inform youth- } \\
\text { friendly services in southern Africa }\end{array}$ & $\begin{array}{l}\text { Males } \\
\& \\
\text { females }\end{array}$ & $\begin{array}{l}68 \text { - females } \\
54 \text { - males } \\
\text { Qualitative: } \\
\text { 8-female interviews } \\
\text { (60 FGDs participants) } \\
7 \text { - male interviews } \\
\text { (47 FGDs participants) }\end{array}$ & $16-25$ years & $\begin{array}{l}\text { Mixed methods: } \\
\text { Qualitative (interviews } \\
\text { \& focus group } \\
\text { discussions); \& } \\
\text { experiments }\end{array}$ \\
\hline $\begin{array}{l}\text { Jennings } \\
\text { et al., } 2017\end{array}$ & Tanzania & $\begin{array}{l}\text { To assess perceived costs saved and costs incurred } \\
\text { from use of HIVST kits in infrequently- or never- } \\
\text { tested Tanzanian men. }\end{array}$ & Males & 23 & $\begin{array}{l}15 \text { years \& } \\
\text { older }\end{array}$ & Qualitative (interviews) \\
\hline $\begin{array}{l}\text { Kelvin } \\
\text { et al., } 2016\end{array}$ & $\begin{array}{l}\text { South } \\
\text { Africa }\end{array}$ & $\begin{array}{l}\text { To document opinions about self-administered at- } \\
\text { home oral HIV testing }\end{array}$ & $\begin{array}{l}\text { Males } \\
\& \\
\text { females }\end{array}$ & $\begin{array}{l}10 \text { - females } \\
10 \text { - males }\end{array}$ & $\begin{array}{l}18 \text { years \& } \\
\text { older }\end{array}$ & Qualitative (interviews) \\
\hline $\begin{array}{l}\text { Knight } \\
\text { et al., } 2017\end{array}$ & $\begin{array}{l}\text { South } \\
\text { Africa }\end{array}$ & $\begin{array}{l}\text { To assess the perceived usability and acceptability } \\
\text { of HIVST among lay users using several self-test } \\
\text { prototypes. }\end{array}$ & $\begin{array}{l}\text { Males } \\
\& \\
\text { females }\end{array}$ & $\begin{array}{l}27 \text { - females; } \\
23 \text { - males }\end{array}$ & $\begin{array}{l}18 \text { years \& } \\
\text { older }\end{array}$ & $\begin{array}{l}\text { (Qualitative } \\
\text { (interviews) }\end{array}$ \\
\hline $\begin{array}{l}\text { Makusha } \\
\text { et al., } 2015\end{array}$ & $\begin{array}{l}\text { South } \\
\text { Africa }\end{array}$ & $\begin{array}{l}\text { To explore: interest in HIV self-testing; potential } \\
\text { distribution channels for HIV self-tests to target }\end{array}$ & $\begin{array}{l}\text { Males } \\
\&\end{array}$ & $\begin{array}{l}\text { 2: Government } \\
\text { Officials; 4: NGOs; 2: }\end{array}$ & $\begin{array}{l}18 \text { years \& } \\
\text { older }\end{array}$ & $\begin{array}{l}\text { Qualitative (in-depth } \\
\text { interviews) }\end{array}$ \\
\hline
\end{tabular}


Table 3 Characteristics of included studies (Continued)

\begin{tabular}{|c|c|c|c|c|c|c|}
\hline $\begin{array}{l}\text { Author \& } \\
\text { year }\end{array}$ & Country & Study aim & Sample & $\begin{array}{l}\text { Number of } \\
\text { participants }\end{array}$ & Age group & Research Method \\
\hline & & $\begin{array}{l}\text { groups; perception of requirements for diagnostic } \\
\text { technologies that would be most amenable to } \\
\text { HIV self-testing and opinions on barriers and } \\
\text { opportunities for HIV-linkage to care after } \\
\text { receiving positive test results }\end{array}$ & females & $\begin{array}{l}\text { Donors; } 3 \text { Academic } \\
\text { Researchers; } 1 \text { Int. } \\
\text { stakeholder }\end{array}$ & & \\
\hline $\begin{array}{l}\text { Martinez } \\
\text { Perez et al., } \\
2016\end{array}$ & $\begin{array}{l}\text { South } \\
\text { Africa }\end{array}$ & $\begin{array}{l}\text { To examine the feasibility and acceptability of } \\
\text { unsupervised oral self-testing for home use in } \\
\text { an informal settlement of South Africa. }\end{array}$ & Males & $\begin{array}{l}11 \text { - females; } \\
9 \text { - males }\end{array}$ & $\begin{array}{l}18 \text { years \& } \\
\text { older }\end{array}$ & $\begin{array}{l}\text { Qualitative (couple } \\
\text { interviews, in-depth in- } \\
\text { terviews, focus group } \\
\text { discussions) }\end{array}$ \\
\hline $\begin{array}{l}\text { Matovu } \\
\text { et al., } 2018\end{array}$ & Uganda & $\begin{array}{l}\text { To explore HIVST perceptions, delivery strategies, } \\
\text { and post-test experiences among pregnant } \\
\text { women and their male partners in Central Uganda. }\end{array}$ & Males & $\begin{array}{l}17 \text { - females; } \\
15 \text { - males }\end{array}$ & $\begin{array}{l}18 \text { years \& } \\
\text { older }\end{array}$ & $\begin{array}{l}\text { Qualitative (in-depth } \\
\text { interviews) }\end{array}$ \\
\hline $\begin{array}{l}\text { Ngure } \\
\text { et al., } 2017\end{array}$ & Kenya & $\begin{array}{l}\text { To address key questions on feasibility, } \\
\text { acceptability and use of HIV self-testing among } \\
\text { HIV-uninfected persons initiating PrEP }\end{array}$ & Males & $\begin{array}{l}10 \text { - females; } \\
20 \text { - males }\end{array}$ & $27-38$ years & $\begin{array}{l}\text { Qualitative (in-depth } \\
\text { interviews; focus group } \\
\text { discussion) \& } \\
\text { qualitative }\end{array}$ \\
\hline $\begin{array}{l}\text { Ritchwood } \\
\text { et al., } 2019\end{array}$ & $\begin{array}{l}\text { South } \\
\text { Africa }\end{array}$ & $\begin{array}{l}\text { To elucidate concerns and issues regarding HIVST } \\
\text { rollout among South African youth }\end{array}$ & $\begin{array}{l}\text { Males } \\
\& \\
\text { females }\end{array}$ & $\begin{array}{l}\text { Phase } 1 \text { (FGDs): } \\
16 \text { females; } \\
19 \text { males, } \\
\text { Phase 2a } \\
\text { (Observations): } \\
10 \text { females; } \\
10 \text { males } \\
\text { Phase } 2 \mathrm{~b} \\
\text { (Observations): } \\
20 \text { females; } \\
20 \text { males }\end{array}$ & 18-24 years & $\begin{array}{l}\text { Mixed methods: } \\
\text { Qualitative (focus } \\
\text { group discussions) \& } \\
\text { observations }\end{array}$ \\
\hline
\end{tabular}

Poor knowledge of HIVST did not vary depending on whether a country was implementing HIVST or not. Although this was the case, once the participants became aware of its benefits, they were willing to utilise HIVST after it was introduced to them and promote its use among their peers $[12,31]$. Some male participants indicated the need to conduct HIVST awareness campaigns to increase HIVST knowledge and ensure the successful implementation $[32,33]$, as illustrated by one participant in Tanzania:

"First, before distributing those test kits there should be a seminar, educating each Tanzanian in general for them to know how to use the kit and then getting the results and what to do after that, this will make someone more aware" [ [32], p. 9].

Such campaigns may be conducted at community levels as well as in person, at clinics or via pamphlets, or through media channels such as television, radio, and newspapers [32].

\section{Acceptability of HIVST}

The evidence on acceptability was reported on in nine studies [11, 12, 25, 26, 31-34, 37]. The majority of men showed a willingness to use HIVST in studies conducted in Malawi [11], Tanzania [32, 33], South Africa [26], and Kenya [37], with most of the participants having administered HIVST in the past in Tanzania [33]. The oral HIVST was preferred over finger-pricking [26], although respondents agreed that HIVST, in general, was easy to use [26, 37]. One male participant in South Africa stated:

"It was easy and good. Well, initially I was a bit nervous because I was just starting. But now I'm getting more comfortable because I've seen how it works" [ [26], p. 4].

The acceptability of HIVST was not influenced by participants' prior knowledge nor awareness of HIVST $[12,32]$ and did not significantly vary by age, marital status, level of education, or socio-economic status [11]. Some men further indicated that they would recommend HIVST to friends and family members [11]. Others thought that their friends who generally resisted HIV testing would be encouraged to try the HIVST model [31], especially because this HIV testing model could be perceived as addressing the barriers associated with the clinic-based HIV testing model [25], as expressed by one male participant in South Africa:

"I would rather not go to the clinic once I know how to use it I can then test myself" [ [26], p. 4]. 
Also, using women who attend ANC clinics to deliver HIVST to their male partners has been seen to be acceptable by men in Uganda and Malawi, and it is perceived to improve partner and couples' HIV testing $[25,34]$.

"I feel like it's acceptable because maybe the day that the woman wants to go to ANC clinic you might not be able to escort her, so she can just bring you the test kits when she is coming back from ANC and the next time she is going for ANC then you can go together" [ [25], p. 4].

\section{Need for HIVST counselling}

The evidence on the importance of counselling prior to using HIVST was reported in eleven articles [12, 24-32, 35]. Studies conducted in Zambia, South Africa, Tanzania, and Malawi indicated that conducting pre-test and post-test counselling is crucial to address potential psychological and physical harm because people are likely to react differently to HIV positive test results. Some may become suicidal or initiate verbal or physical partner violence due to their fear and/or poor knowledge of how to manage the HIV positive result [24, 25, 29, 30, 32]. Below are some comments made by male participants in Zambia and South Africa:

"If a person is positive, they need to find people who can help [them], so that they can be comforted and not have the feeling of saying 'why have I been found positive or what can I do?'.. . Others commit suicide and they tell themselves they are better off dying than suffering with the illness. So, they should be counselled so that they can understand" [ [24], p. 8].

"I will just take the rope and hang myself because I know there is no one who will shout at me. Even if I'm crying, no one will comfort me, but here are things [ARVs] to prevent [death] and even the government is bringing the pills and you can prevent [death] with them ... because the disease doesn't kill you if you can go to the counsellors, the counsellor will tell you that okay, alright, you have the disease and the disease doesn't kill you" [ [29], p. 8].

Studies conducted in Malawi, Tanzania, Uganda, and South Africa also supported the importance of pre- and post- HIV counselling for men to ensure that men are not left isolated [11, 12, 26, 28, 29, 31, 35]. The pre-HIVST counselling would likely assess men's readiness to respond to a potential HIV positive test outcome [32]. Some men, as noted in the comment made by males in Tanzania, indicated that they would educate their peers to take necessary steps, like seeing a healthcare worker for confirmatory results, as well as starting ART treatment [31]:

"If it will not be possible to check pressure then there is another way where you look at how the person is... Through conversation with the client you are needed to look at him and say that from my questions and his responses is he not going to commit suicide if we give him this instrument" [ [32], p. 4].

"I will advise him by telling him that it's alright you have tested yourself alone but you cannot stay alone you must go to the doctors to be counselled" [ [31], p. 1192].

While men acknowledged the importance of preHIVST counselling, most did not desire the face-to-face counselling with healthcare providers $[11,12]$, but appreciated alternative forms of counselling that would maintain their privacy, such as sharing information via mobile test messaging services, paper-based counselling information, or phone calls [26]. Despite these preferred methods of counselling, one male from the nongovernmental organisation (NGO) sector in South Africa emphasised that HIVST poses challenges as far as counselling is concerned and that there should not be any HIV testing without counselling, as this is an important component for HIV self-testers:

"But most important... we need to ensure there will be constant access to counselling. We should not undermine the value of counselling. That is why whenever we talk about HIV testing, or whatever the case might be, we talk HIV counselling and testing...You will never find HIV testing that does not have the $C$, so the C for me is a crucial part" [ [27], p. 5].

\section{Confidentiality of HIVST}

The HIV self testing model and confidentiality were discussed in eight articles [12, 25-28, 31, 32, 37]. Due to a perceived lack of privacy, confidentiality, and the stigma in healthcare facilities, men believed that the HIVST presented a feasible alternative for them to test for HIV [12, 25, 26, 31, 32, 37]. Privacy and confidentiality were primary reasons men preferred HIVST [31], as noted by a male participant in a study conducted in Tanzania:

"It will give people privacy as you can take it and go test anywhere in privacy as most of the time people fear going to health clinics as they may meet someone they know or they know a worker there who after testing might go spread the results" [ [31], p. 1191]. 
In addition to that, some men preferred HIVST so that they could know their own HIV test results first, especially if they have had multiple sexual partners, as revealed by a male participant in Malawi:

"... you just go out secretly and follow the method and right there it's as easy as drinking a glass of water. You quickly place it in the bottle and hide it since you want to check yourself first (participants laugh). When the results are out you will check them, and you will know the outcome yourself right?" [ [25], p. 4].

While HIVST seems to be beneficial for men, a study conducted in South Africa cautioned that there still remains challenges where men have to collect HIVST kits at healthcare facilities when this programme is upscaled. The suggestion was that it was important to establish distribution points, especially to encourage men to utilise the programme [12].

\section{Convenience of HIVST}

Evidence of the convenience of HIVST was reported in nine studies [12, 26, 29, 32-37]. Specifically, men preferred HIVST because it was viewed as efficient and convenient [26, 29, 32, 33, 37]. It was also a non-disruptive testing option [33], especially important for those men who, due to long working hours, had difficulty attending clinic settings [12, 32-34, 36]. A clinic setting was also perceived as being time-consuming, as a result of long queues, waiting times [12], and travelling [33]. As noted by male participants in South Africa, Kenya, and Uganda:

"It's convenient, you don't have to go to the clinic and be in a long line, and end up not getting tested in the end, because they work within certain time frames for certain services" [ [12], p. 4].

"I think it is right because sometimes there are queues at clinics. And also I am afraid that people will see me in that queue and know that I came for HIV test whereas at home it is easy and everything you do is your secret" [ [26], p.4].

"With HIV self-testing you do not require any bus fare, anytime you can just test yourself" [ [37], p.6].

Therefore, the convenience of HIVST stems from the fact that men can easily use HIVST kits at their own convenience, as well as in the comfort of their homes [34]. This addresses the gap posed by a lack of time to attend clinic settings [34].

\section{Accuracy of HIVST}

The accuracy of HIVST was discussed in five articles [30, 32-34, 37]. Due to the fact that HIVST requires a confirmatory HIV test, this reduces trust in the HIVST results [32], as some men remained sceptical whether or not the HIVST can really test for HIV, especially in instances where saliva is used (oral) instead of a blood sample:

"I asked myself 'is this really true"? Can really a person just get that 'spoon' [the kit] and pass it on the gum and then... [he spreads his hands] and test for HIV?" [ [34]. p.4].

Due to doubts about the accuracy of HIVST, some men believed that a clinic setting was actually a better choice for HIV testing because they do not believe that HIVST results are accurate.

"How sure are you about this kit? I don't trust this kit. Why should I have to go back to the clinic and get tested again after using [the HIVST kit] and [to potentially] test positive? I cannot use [the HIVST]. I'd rather go to the clinic and use blood test, not [the blood HIVST]" [ [30], p.6].

Men who are not well-educated were perceived to have a high risk of misinterpreting or getting inaccurate results due to their poor capacity to administer the HIVST kit [32, 33], this was illustrated by a male participant from Tanzania:

"That is the challenge which I will get as I will not be confident as if I will go to the hospital ... I mean I will not be more confident that the instrument has shown correctly the results.. . Perhaps there may be a certain mistake which I have made or there may be something which I have done wrong ... Because I may do it wrong and it shows me that I am HIV negative while I am HIV positive, so don't trust myself" [ [32], p.8].

However, men's attitudes towards seeking an HIV confirmatory test based on the results of HIVST was high:

"Truly if I see two lines have appeared I will be ready to move from this place to the responsible place to verify my results" [ [32], p.8].

Although very low in numbers, some men indicated that they would not seek HIV confirmatory test after the HIVST and linkage to ART treatment due to confidentiality and stigma concerns posed by attending the clinic setting [32]. 


\section{Discussion}

This study revealed evidence regarding men's perspectives on HIVST in SSA. The results show that men's knowledge of HIVST remains low in SSA, despite the high acceptability shown when the HIVST was introduced. The study also found that while HIVST provided men with alternative testing model, given its confidentiality and convenience, there remained issues as far as pre- and post-counselling, given the potential psychological and physical harm resulting from different reactions to HIV positive test results. Due to their low confidence in administering HIVST and the use of saliva to test for HIV (oral HIV test), some men do not trust the accuracy of HIVST results. This suggests the importance of educating men about the HIVST model.

While several studies have documented the high acceptance of HIVST among populations [16, 38-40] and its convenience $[41,42]$, this, to our knowledge, is the first systematic review and meta-synthesis to assess men's perspectives on HIVST in SSA. While education is key to changing men's perspectives and improving HIV knowledge, this study further revealed that HIV self-testing is critical to addressing issues of confidentiality and convenience $[9,16,43$, 44]. Therefore, this strategy is key to supporting the UNAIDS plans aimed at addressing masculinity issues, one of which is men's engagement in HIV testing [45].

The findings of this study, consistent with the findings of other studies conducted in resource-limited settings, revealed that, given the many barriers associated with HIV testing in a clinic setting, more men preferred to engage themselves with HIV testing services that were conducted outside this setting [16, 46-51]. In addition to that, the HIVST model further empowers young people and sexually active individuals to be independent and have the option to choose the location and timing of the test and to control the disclosure of their results [36]. This review further revealed that the oral HIVST model is acceptable among men, supporting the findings of other studies conducted among other study populations in different settings [11, 52]. Like other studies in different settings, this study also found similar concerns regarding the need for HIVST counselling $[53,54]$, as well as the potential for incorrect interpretation of HIV self-testing results [55]. Notwithstanding the concerns that men raised, the findings support the theory that the HIVST model has the potential to increase the uptake of HIV testing, especially among men. However, the concerns mentioned above need to be addressed.

\section{Strengths and limitations}

Although the searches included a wide range of databases, the overall search strategy may have been biased towards public health and social sciences. While the review included any article published in any language, our search was conducted using only English terms. Nevertheless, we believe that the search strategy was comprehensive in reviewing public health and social sciences literature on men's perspectives on HIVST in SSA. All included studies underwent quality appraisal using an approved tool, the MMAT. This review also included studies conducted in countries in SSA that are not implementing the HIVST initiative, however, these are not likely to have influenced our findings because similar patterns of men's perspectives on HIVST were observed across all the included studies conducted in different countries. Given that only a handful of studies met our inclusion criteria, the findings of this review may not be generalised across all men in SSA. However, understanding men's perceptions on HIVST is important.

\section{Recommendations for future research}

The study findings show that the HIVST has the potential to improve men's uptake of HIV testing in SSA [56] as it has been shown to attract more men in similar settings [11, 57-59]. The research on HIVST is still in its infancy stages, especially in the SSA region. This is a reason why only a few studies met the inclusion criteria, which focussed specifically on men. Therefore, it is recommended that more studies should be conducted among men regarding HIVST. The focus on men's perspectives on HIVST is important to understand the challenges and opportunities as far as HIVST implementation is concerned.

\section{Implications for practice}

This study revealed that there is high acceptance of HIVST among men in SSA, although prior knowledge of HIVST was not widespread. This suggests the importance of implementing community-level campaigns aimed at educating men about HIVST, given the potential of this HIV testing strategy to attract hard-to-reach men. When the implementation of HIVST is up-scaled, the implementers should develop strategies aimed at ensuring that all potential HIVST users are counselled and supported to assess their readiness to use HIVST, as well as the potential psychological and physical risks associated with a positive HIV test result.

\section{Conclusion}

The introduction of the HIVST model is important for improving men's uptake of HIV testing services. While HIVST addresses men's barriers, such as confidentiality and convenience regarding attending clinic settings, there remains a gap in terms of HIVST counselling and accuracy, with the knowledge remaining poor among potential users. There also remains a gap in research to address the risks associated with HIVST testing strategies versus the potential benefits, especially among men in SSA. 


\section{Appendix}

Table 4 Sub-Saharan African search filter

PubMed

("hiv"[MeSH Terms] OR "hiv"[All Fields]) AND testing [All Fields]) OR (("hiv"[MeSH Terms] OR "hiv"[All Fields]) AND self-testing [All Fields])) OR (("hiv"[MeSH Terms] OR "hiv"[All Fields]) AND ("ego"[MeSH Terms] OR "ego"[All Fields] OR "self"[All Fields]) AND testing [All Fields])) AND ("men"[MeSH Terms] OR "men"[All Fields])) OR ("male"[MeSH Terms] OR "male"[All Fields])) AND ("africa"[MeSH Terms] OR "africa"[All Fields])) OR "Sub-Saharan Africa"[All Fields]) OR ("angola"[MeSH Terms] OR "angola"[All Fields])) OR ("benin"[MeSH Terms] OR "benin"[All Fields])) OR ("botswana"[MeSH Terms] OR "botswana"[All Fields])) OR ("burkina faso"[MeSH Terms] OR ("burkina"[All Fields] AND "faso"[All Fields]) OR "burkina faso"[All Fields])) OR ("burundi"[MeSH Terms] OR "burundi"[All Fields])) OR ("cameroon"[MeSH Terms] OR "cameroon"[All Fields])) OR ("cabo verde"[MeSH Terms] OR ("cabo"[All Fields] AND "verde"[All Fields]) OR "cabo verde"[All Fields] OR ("cape"[All Fields] AND "verde"[All Fields]) OR "cape verde"[All Fields])) OR "Central African Republic"[All Fields]) OR ("chad"[MeSH Terms] OR "chad"[All Fields])) OR ("comoros"[MeSH Terms] OR "comoros"[All Fields])) OR "Congo brazzaville"[All Fields]) OR "Democratic republic of congo"[All Fields]) OR "Cote d'Ivoire"[All Fields]) OR ("djibouti"[MeSH Terms] OR "djibouti"[All Fields])) OR "Equatorial Guinea"[All Fields]) OR ("eritrea"[MeSH Terms] OR "eritrea"[All Fields])) OR ("ethiopia"[MeSH Terms] OR "ethiopia"[All Fields])) OR ("gabon"[MeSH Terms] OR "gabon"[All Fields])) OR ("gambia"[MeSH Terms] OR "gambia"[All Fields])) OR ("ghana"[MeSH Terms] OR "ghana"[All Fields])) OR ("guinea"[MeSH Terms] OR "guinea"[All Fields])) OR "Guinea-Bissau"[All Fields]) OR ("kenya"[MeSH Terms] OR "kenya"[All Fields])) OR ("lesotho"[MeSH Terms] OR "lesotho"[All Fields])) OR ("liberia"[MeSH Terms] OR "liberia"[All Fields])) OR ("madagascar"[MeSH Terms] OR "madagascar"[All Fields])) OR ("malawi"[MeSH Terms] OR "malawi"[All Fields])) OR ("mali"[MeSH Terms] OR "mali"[All Fields])) OR ("mauritania"[MeSH Terms] OR "mauritania"[All Fields])) OR ("mauritius"[MeSH Terms] OR "mauritius"[All Fields])) OR ("mozambique"[MeSH Terms] OR "mozambique"[All Fields])) OR ("namibia"[MeSH Terms] OR "namibia"[All Fields])) OR ("niger"[MeSH Terms] OR "niger"[All Fields])) OR ("nigeria"[MeSH Terms] OR "nigeria"[All Fields])) OR ("reunion"[MeSH Terms] OR "reunion"[All Fields])) OR ("rwanda"[MeSH Terms] OR "rwanda"[All Fields])) OR "Sao Tome and Principe"[All Fields]) OR ("senegal"[MeSH Terms] OR "senegal"[All Fields])) OR ("seychelles"[MeSH Terms] OR "seychelles"[All Fields])) OR ("sierra leone"[MeSH Terms] OR ("sierra"[All Fields] AND "leone"[All Fields]) OR "sierra leone"[All Fields])) OR ("somalia"[MeSH Terms] OR "somalia"[All Fields])) OR "South Africa"[All Fields]) OR ("sudan"[MeSH Terms] OR "sudan"[All Fields])) OR ("swaziland"[MeSH Terms] OR "swaziland"[All Fields])) OR ("tanzania"[MeSH Terms] OR "tanzania"[All Fields])) OR ("togo"[MeSH Terms] OR "togo"[All Fields])) OR ("uganda"[MeSH Terms] OR "uganda"[All Fields])) OR "Western Sahara"[All Fields]) OR ("zambia"[MeSH Terms] OR "zambia"[All Fields])) OR ("zimbabwe"[MeSH Terms] OR "zimbabwe"[All Fields])) OR "west africa"[All Fields]) OR "east africa"[All Fields]) OR "southern africa"[All Fields])

\begin{abstract}
Abbreviations
HIVST: HIV self-testing; MeSH: Medical Subject Headings; MMAT: The Mixed Method Appraisal Tool; PCC: Population, Concept, and Context; PRISMA: We used the Preferred Reporting Items for Systematic Reviews and MetaAnalysis; SSA: Sub-Saharan Africa; UCTD: Union Catalogue of Theses and Dissertations; UNAIDS: The AIDS and AIDS; WHO: World Health Organisation
\end{abstract}

\section{Acknowledgements}

The authors would like to thank the School of Nursing and Public Health, University of KwaZulu-Natal, Durban, South Africa.

\section{Authors' contributions}

$\mathrm{MH}$ conceptualised, designed, and prepared the initial draft of the study, which was reviewed by $\mathrm{KH}, \mathrm{TM}-\mathrm{T}$, and CM. SM contributed in the abstract, full article screening, and data extraction. All the authors reviewed the draft and approved the final version of the manuscript.

\section{Funding}

The study was funded by the University of KwaZulu-Natal, College of Health. Sciences. The funding body had no role in the design of the study, data collection, analysis, and interpretation of data, nor in writing the manuscript.

\section{Availability of data and materials}

All the data analysed and reported in this paper were from published literature, which is already in the public domain.

\section{Ethics approval and consent to participate}

This study does not include any animal or human participants. Ethics approval and consent to participate are not applicable.

\section{Consent for publication}

Not applicable.

\section{Competing interests}

The authors declare that they have no competing interests.

\section{Author details}

${ }^{1}$ Discipline of Public Health Medicine, School of Nursing and Public Health, University of KwaZulu-Natal, Durban, South Africa. ${ }^{2} \mathrm{CIHR}$ Canadian HIV Trials Network, Vancouver, BC, Canada.

Received: 15 April 2019 Accepted: 8 January 2020

Published online: 15 January 2020

\section{References}

1. Staveteig S, Wang S, Head SK, Bradley SE, Nybro E. Demographic patterns of HIV testing uptake in sub-Saharan Africa. DHS comparative reports no. 30. Calverton, Maryland: ICF International; 2013.

2. Tabana H, Doherty T, Swanevelder S, Lombard C, Jackson D, Zembe W, et al. Knowledge of HIV status prior to a community HIV counseling and testing intervention in a rural district of South Africa: results of a community based survey. BMC Infect Dis. 2012;12:73.

3. Ehrhardt AA, Sawires S, McGovern T, Peacock DWM. Gender, empowerment, and health: what is it? How does it work? J Acquir Immune Defic Syndr. 2009;51(3):96

4. Kanters S, Nansubuga M, Mwehire D, Odiit M, Kasirye M, Musoke W, et al. Increased mortality among HIV-positive men on antiretroviral therapy: survival differences between sexes explained by late initiation in Uganda. HIV/AIDS Res Palliative Care. 2013:5:111.

5. Mills EJ, Bakanda C, Birungi J, Chan K, Hogg RS, Ford N, et al. Male gender predicts mortality in a large cohort of patients receiving antiretroviral therapy in Uganda. J Int AIDS Soc. 2011;14(1):52.

6. Druyts E, Dybul M, Kanters S, Nachega J, Birungi J, Ford N, et al. Male sex and the risk of mortality among individuals enrolled in antiretroviral therapy programs in Africa: a systematic review and meta-analysis. AIDS 2013;27(3):417-25

7. UNAIDS. 90-90-90: an ambitious treatment target to help end the AIDS epidemic. Geneva: Joint United Nations Programme on HIV/AIDS; 2014.

8. DiCarlo AL, Mantell JE, Remien RH, Zerbe A, Morris D, Pitt B, et al. 'Men usually say that HIV testing is for women': gender dynamics and perceptions of HIV testing in Lesotho. Culture Health Sexuality. 2014; 16(8):867-82

9. Hensen B, Lewis J, Schaap A, Tembo M, Mutale W, Weiss H, et al. Factors associated with HIV-testing and acceptance of an offer of home-based testing by men in rural Zambia. AIDS Behav. 2015;19(3):492-504.

10. Hensen B, Taoka S, Lewis JJ, Weiss HA, Hargreaves JJA. Systematic review of strategies to increase men's HIV-testing in sub-Saharan Africa. AIDS. 2014; 28(14):2133.

11. Choko AT, Desmond N, Webb EL, Chavula K, Napierala-Mavedzenge S, Gaydos CA, et al. The uptake and accuracy of oral kits for HIV self-testing in high HIV prevalence setting: a cross-sectional feasibility study in Blantyre, Malawi. PLoS Med. 2011;8(10):e1001102.

12. Harichund C, Moshabela M, Kunene P, Abdool KQ. Acceptability of HIV selftesting among men and women in KwaZulu-Natal, South Africa. AIDS Care. 2018;31(2):186-92.

13. Figueroa C, Johnson C, Verster A, Baggaley RJA. Behavior, attitudes and acceptability on HIV self-testing among key populations: a literature review. AIDS Behav. 2015;19(11):1949-65. 
14. Harding-Esch EM, Hollis E, Mohammed H, Saunders JM. Self-sampling and self-testing for STIs and HIV: the case for consistent nomenclature. Sex Transm Infect. 2016;93(2):445-8.

15. Wood BR, Ballenger C, Stekler JD. Arguments for and against HIV selftesting. HIV/AIDS Res Palliative Care. 2014;6(4):117-26.

16. Hongwa M, Mashamba-Thompson T, Makhunga S, Hlongwana K. Mapping evidence of intervention strategies to improving men's uptake to HIV testing services in sub-Saharan Africa: a systematic scoping review. BMC Infect Dis. 2019;19(496):1-13.

17. Populations Services International. HIV Self-testing Africa Initiative. PSI; 2017. https://www.psi.org/star-hiv-self-testing-africa/. Accessed 12 Mar 2019

18. Hlongwa M, Hlongwana K. Men's perspectives on HIV self-testing in sub-Saharan Africa: a qualitative systematic review protocol. JBI Database of Syst Rev Implement Rep. 2019;17(0):1-5. https://doi.org/10. 11124/JBISRIR-D-19-00097.

19. Moher D, Liberati A, Tetzlaff J, Altman DG, Group TP. Preferred reporting items for systematic reviews and meta-analyses: the PRISMA statement. PLoS Med. 2009;6(7):e1000097.

20. Clarivate Analytics. EndNote library version 7. 2016. https://endnote.com/. Accessed 20 Feb 2019.

21. Hong QN, Pluye P, Fàbregues S, Bartlett G, Boardman F, Cargo M, et al. Mixed methods appraisal tool (MMAT), version 2018. Canada: Canadian Intellectual Property Office; 2018. http://mixedmethodsappraisaltoolpublic. pbworks.com/w/file/fetch/127425851/MMAT_2018_criteria-manual_2018-0404.pdf. Accessed 10 Mar 2019

22. Thomas J, Harden A. Methods for the thematic synthesis of qualitative research in systematic reviews. BMC Med Res Methodol. 2008:8(1):45.

23. Ltd QIP. NVivo qualitative data analysis software version 11; 2011.

24. Chipungu J, Bosomprah S, Zanolini A, Thimurthy H, Chilengi R, Sharma A, et al. Understanding linkage to care with HIV self-test approach in Lusaka, Zambia - a mixed method approach. PLoS One. 2017;12(11):e0187998.

25. Choko AT, Kumwenda MK, Johnson CC, Sakala DW, Chikalipo MC, Fielding $\mathrm{K}$, et al. Acceptability of woman-delivered HIV self-testing to the male partner, and additional interventions: a qualitative study of antenatal care participants in Malawi. J Int AIDS Soc. 2017;20(1):21610.

26. Knight L, Makusha T, Lim J, Peck R, Taegtmeyer M, van Rooyen H. "I think it is right": a qualitative exploration of the acceptability and desired future use of oral swab and finger-prick HIV self-tests by lay users in KwaZulu-Natal, South Africa. BMC Res Notes. 2017;10(1):486.

27. Makusha T, Knight L, Taegtmeyer M, Tulloch O, Davids A, Lim J, et al. HIV self-testing could "revolutionize testing in South Africa, but it has got to be done properly": perceptions of key stakeholders. PLoS One. 2015;10(3):e0122783.

28. Martinez Perez G, Cox V, Ellman T, Moore A, Patten G, Shroufi A, et al. I know that i do have HIV but nobody saw me': Oral HIV Self-testing in an informal settlement in South Africa. PloS One. 2016;11(4):e0152653.

29. Kelvin EA, Cheruvillil S, Christian S, Mantell JE, Milford C, Rambally-Greener L, et al. Choice in HIV testing: the acceptability and anticipated use of a selfadministered at-home oral HIV test among south Africans. Afr J AIDS Res. 2016;15(2):99-108.

30. Ritchwood TD, Selin A, Pettifor A, Lippman SA, Gilmore H, Kimaru L, et al. HIV self-testing: south African young adults' recommendations for ease of use, test kit contents, accessibility, and supportive resources. BMC Public Health. 2019;19(1):123.

31. Conserve DF, Alemu D, Yamanis T, Maman S, Kajula L. "he told me to check my health": a qualitative exploration of social network influence on men's HIV testing behavior and hiv self-testing willingness in Tanzania. Am J Mens Health. 2018;12(5):1185-96.

32. Conserve DF, Muessig KE, Maboko LL, Shirima S, Kilonzo MN, Maman S, et al. Mate Yako Afya Yako: formative research to develop the Tanzania HIV self-testing education and promotion (Tanzania STEP) project for men. PLoS One. 2018;13(8):e0202521.

33. Jennings $L$, Conserve DF, Kajula L, Iwelunmor J, Maman S. Perceived cost advantages and disadvantages of purchasing HIV self-testing kits among urban Tanzanian men: An inductive content analysis. J AIDS Clin Res. 2017; 8(8):725.

34. Matovu JKB, Kisa R, Buregyeya E, Chemusto H, Mugerwa S, Musoke W, et al. 'If I had not taken it [HIVST kit] home, my husband would not have come to the facility to test for HIV': HIV self-testing perceptions, delivery strategies, and post-test experiences among pregnant women and their male partners in Central Uganda. Global Health Action. 2018;11(1):1503784.
35. Burke VM, Nakyanjo N, Ddaaki W, Payne C, Hutchinson N, Wawer MJ, et al. HIV self-testing values and preferences among sex workers, fishermen, and mainland community members in Rakai, Uganda: a qualitative study. PLoS One. 2017;12(8):e0183280.

36. Indravudh PP, Sibanda EL, d'Elbee M, Kumwenda MK, Ringwald B, Maringwa $\mathrm{G}$, et al. I will choose when to test, where I want to test': investigating young people's preferences for HIV self-testing in Malawi and Zimbabwe. AIDS. 2017;31(3):S203-s12.

37. Ngure K, Heffron R, Mugo N, Thomson KA, Irungu E, Njuguna N, et al. Feasibility and acceptability of HIV self-testing among pre-exposure prophylaxis users in Kenya. J Int AIDS Soc. 2017;20(1):21234

38. Napierala Mavedzenge S, Baggaley R. EL. C. a review of self-testing for HIV: research and policy priorities in a new era of HIV prevention. Clin Infect Dis. 2013;57(1):126-38.

39. Thirumurthy H, Masters SH, Mavedzenge SN, Maman S, Omanga E, Agot K. Promoting male partner HIV testing and safer sexual decision making through secondary distribution of self-tests by HIV-negative female sex workers and women receiving antenatal and post-partum care in Kenya: a cohort study. Lancet HIV. 2016;3(6):e266-74.

40. Figueroa C, Johnson C, Verster A, Baggaley R. Attitudes and acceptability on HIV self-testing among key populations: a literature review. AIDS Behav. 2015;19(11):1949-65.

41. Harichund C, Moshabela M. Acceptability of HIV self-testing in sub-Saharan Africa: scoping study. AIDS Behav. 2018;22(2):560-8.

42. Kebede B, Abate T, M D. HIV self-testing practices among health care workers: feasibility and options for accelerating HIV testing services in Ethiopia. Pan Afr Med J. 2013;15:50.

43. Sharma M, Barnabas RV, Celum C. Community-based strategies to strengthen men's engagement in the HIV care cascade in sub-Saharan Africa. PLoS Med. 2017;14(4):e1002262.

44. Harichund C, Moshabela M, Kunene P, Abdool KQ. Acceptability of HIV selftesting among men and women in KwaZulu-Natal, South Africa. AIDS Care. 2018;31:1-7.

45. UNAIDS. Ending AIDS: Progress towards the 90-90-90 targets. Global AIDS update. 2017. https://www.unaids.org/sites/default/files/media_asset/ Global_AIDS_update_2017_en.pdf. Accessed 27 Mar 2019.

46. Wolff B, Nyanzi B, Katongole G, Ssesanga D, Ruberantwari A. J. W. evaluation of a home-based voluntary counselling and testing intervention in rural Uganda. Health Policy Plan. 2005;20(2):109-16.

47. Fauk N, Sukmawati A, Berek P, Ernawati, Kristanti E, Wardojo SS, et al. Barriers to HIV testing among male clients of female sex workers in Indonesia. Int J Equity Health. 2018;17:68.

48. Fylkesnes K, Siziya S. A randomized trial on acceptability of voluntary HIV counseling and testing. Trop Med Int Health. 2004;9(5):566-72.

49. Irwin $\mathrm{KL}$, Valdiserri RO, Holmberg SD. The acceptability of voluntary HIV antibody testing in the United States: a decade of lessons learned. AIDS. 1996;10(4):1707-11.

50. Kim YM, Marangwanda C, Kols A. Quality of counselling of young clients in Zimbabwe. East Afr Med J. 1997;74:514-8.

51. Martinez O, Carballo-Dieguez A, Ibitoye M, Frasca T, Brown W, Balan I. Anticipated and actual reactions to receiving HIV positive results through self-testing among gay and bisexual men. AIDS Behav. 2014;18(12):2485-95.

52. Ochako R, Vu L, Peterson K. Insights into potential users and messaging for HIV oral self-test kits in Kenya, final report. Washington, DC: International Initiative for Impact Evaluation (3ie); 2014

53. Ng OT, Chow AL, Lee VJ, Chen MI, Win MK, Tan HH, et al. Accuracy and user-acceptability of HIV self-testing using an oral fluid-based HIV rapid test. PLoS One. 2012;7(9):e45168.

54. Bilardi JE, Walker S, Read T, Prestage G, Chen MY, Guy R, et al. Gay and bisexual men's views on rapid self-testing for HIV. AIDS Behav. 2013;17(6): 2093-9.

55. Ortblad KF, Musoke DK, Ngabirano T, Nakitende A, Haberer JE, McConnell M, et al. Female sex workers often incorrectly interpret HIV self-test results in Uganda. J Acquir Immune Def Syndr (1999). 2018;79(1):e42.

56. Kakuhikire B, Suquillo D, Atuhumuza E, Mushavi R, Perkins JM, Venkataramani AS, et al. A livelihood intervention to improve economic and psychosocial well-being in rural Uganda: longitudinal pilot study. J Soc Aspects HIV/AIDS. 2016;13(1):162-9.

57. Henley C, Forgwei G, Welty T, Golden M, Adimora A, Shields R, et al. Scaleup and case-finding effectiveness of an HIV partner services program in Cameroon. Sex Transm Dis. 2013:40(12):909-14. 
58. Kurth AE, Lally MA, Choko AT, Inwani IW, F JD. HIV testing and linkage to services for youth. J Int AIDS Soc. 2015;18(2 Suppl 1):19433.

59. MacPherson P, Lalloo DG, Webb EL, Maheswaran H, Choko AT, Makombe SD, et al. Effect of optional home initiation of HIV care following HIV selftesting on antiretroviral therapy initiation among adults in Malawi. JAMA. 2014;312(4):372.

\section{Publisher's Note}

Springer Nature remains neutral with regard to jurisdictional claims in published maps and institutional affiliations.

Ready to submit your research? Choose BMC and benefit from:

- fast, convenient online submission

- thorough peer review by experienced researchers in your field

- rapid publication on acceptance

- support for research data, including large and complex data types

- gold Open Access which fosters wider collaboration and increased citations

- maximum visibility for your research: over $100 \mathrm{M}$ website views per year

At BMC, research is always in progress.

Learn more biomedcentral.com/submissions 